\title{
El cuerpo de la imagen y la locura en Aby Warburg. Una reflexión a partir de fuentes renacentistas
}

\section{Fabián Ludueña Romandini}

Universidad de Buenos Aires - Consejo Nacional de Investigaciones Científicas y Técnicas - Universidad Argentina de la Empresa, Argentina

\begin{abstract}
Resumen
El presente artículo tiene como propósito interrogarse sobre la matriz conceptual según la cual Aby Warburg interpretó tanto El Nacimiento de la Primavera como la Primavera de Sandro Botticelli. Por un lado, proponemos un análisis del papel desempeñado por la poesía del dolce stil nuovo y el neoplatonismo en la comprensión warburguiana de las alegorías de Botticelli. Por otro lado, intentamos dar cuenta de la significación filosófica de la hipótesis explicativa de Warburg a través de un estudio del comentario de Marsilio Ficino al poema Donna me prega de Guido Cavalcanti. La interpretación de Ficino toma como base la noción de spiritus y la desubjetivación de los amantes en beneficio de las potencias cosmológicas. De esta manera, la forclusión del cuerpo resulta la condición de posibilidad del fantasma como auténtico objeto de deseo. Esta interpretación es sancionada por la original apropiación de Ficino de la teoría platónica de las dos Venus (celestial y vulgar). Finalmente, avanzamos la hipótesis según la cual la escisión de las dos Venus en la tradición neoplatónica marca un hito en la historia de la metafísica y juega un papel preponderante en la comprensión que Warburg tendrá de su propio período de internación psiquiátrica en Kreuzlingen desde 1921 a 1924.
\end{abstract}

\section{The body of the image and madness in Aby Warbug. A reflection from Renaissance sources}

\begin{abstract}
The following article intends to inquire into the conceptual framework according to which Aby Warburg interpreted both Sandro Botticelli's Birth of Venus and Primavera. On one hand, we propose an analysis of the role played by the poetry of the dolce stil nuovo and neoplatonism as a means of tackling the warburguian understanding of Botticelli's allegories. On the other hand, we try to grasp the philosophical meaning of Warburg's hypotheses by studying Marsilio Ficino's commentary to Guido Calvacanti's poem Donna me prega. Ficino's interpretation is founded on the notion of spiritus
\end{abstract}

Palabras clave Fantasma Ficino Locura Venus Warburg

Keywords

Phantasm Ficino Madness

Venus Warburg 
1. Para un estudio de la locura de Warburg a partir de los textos (cartas, anotaciones, bibliografía) que el propio Aby produjo durante su período de internación en Kreuzlingen, cfr. Ludueña Romandini: 2017. and the desubjectification of the lovers in favour of the cosmological forces. In this way, the foreclosure of the body is presented as the condition of possibility for the phantasm to become the authentic object of desire. This interpretation is sanctioned by Ficino's original appropriation of the Platonic theory of the two Venuses (celestial and vulgar). Finally, we advance the hypothesis that the splitting between the two Venuses in the neoplatonic tradition is a landmark in the history of metaphysics and plays a fundamental role in the way that Warburg will understand his own period of psychiatric reclusion in Kreuzlingen since 1921 to 1924.

\section{El comentario de Marsilio Ficino (1433-1499) a Guido Cavalcanti (1255-1300) como ideario de la concepción warburguiana de la figura de Venus en Botticelli}

Entre los años 1921 y 1924 Aby Warburg tuvo su acercamiento liminar con la locura de la que testimonian sus años en la clínica Bellevue de Kreuzlingen bajo el cuidado de Ludwig Binswanger. A pesar de los necesarios meandros que habremos de recorrer en este texto, nuestro objetivo yace en este punto. No nos proponemos esclarecer la obra de Aby Warburg ni, mucho menos, la fenomenología psiquiátrica de su locura. Al contrario, nuestro objetivo es mucho más acotado: intentaremos captar la significación histórica, desde un punto de vista filosófico, del período de su así denominada locura. Para ello nos serviremos de un hilo de Ariadna un tanto inesperado pero que puede conducirnos por un recto camino: me refiero a ciertos matices de la interpretación que Aby Warburg ha dado tanto del Nacimiento de la Primavera como de la Primavera de Sandro Botticelli. Particularmente, pondremos atención en algunas fuentes renacentistas que pueden haber nutrido la exégesis de Warburg.

Para lograr este punto, no consideraremos en esta ocasión las interpretaciones posteriores a Warburg sobre estas obras pictóricas ni juzgaremos la corrección de la exégesis warburguiana de Botticelli. Esto implica que nuestro trabajo no se desarrollará bajo la égida de la iconología o de la historia del arte sino de la filosofía. Tomaremos, por tanto, las palabras de Warburg como dispositivo discursivo autosuficiente para el objetivo minimalista que nos proponemos: comprender algunas articulaciones metafísicas de la locura de Warburg como índices de su tiempo histórico.

Cabe añadir que, para este propósito, no utilizaremos los textos de diversa índole producidos por Warburg durante el transcurso de su locura sino, al contrario, un texto publicado previamente. ${ }^{1}$ La intención es mostrar que al menos algunos de los dilemas que afectaron al período de la locura de Warburg conforman una matriz de inteligibilidad que permea la totalidad de su obra. Estimamos esta característica, vale aclararlo, como un rasgo altamente virtuoso. No hace falta tener ningún romanticismo por la locura (tentación a la que es necesario, a toda costa, evitar entregarse) para detectar en ella una lógica rigurosa. Más aún podrá discernirse, entonces, en otros textos warburguianos los elementos de lo que hemos denominado una misma matriz conceptual.

En 1898, Aby Warburg publica en la revista Das Museum una recapitulación y una puesta a punto de sus tesis centrales sobre Botticelli:

La fuente de inspiración para el Nacimiento de la Primavera y para la asíllamada Primavera fue Angelo Poliziano, el amigo erudito de Lorenzo de Médici así como compañero poeta. En las estancias italianas de la Giostra de Poliziano-su poema en alabanza de Giuliano- la Venus nacida de la espuma con las Gracias, las diosas de la Primavera, Céfiro y Flora viven de nuevo, en imitación de los poetas de la antigüedad. Existen fundamentos históricos y externos de que la misma causa 


\begin{abstract}
que llevó a Poliziano a escribir la Giostra- la adoración de Giuliano de la "ninfa" Simonetta- asimismo incitó a Sandro a darle forma pictórica, por primera vez, al mismo complejo de ideas mitológicas (mythologischen Ideenkreis). La imagen de Simonetta Vespucci, que había muerto joven y a quien tanto Lorenzo como Giuliano habían amado de manera caballeresca y reverente al igual que Dante a Beatriz o Petrarca a Laura, debía de ser capturada en el símbolo consolador de la Dama Venus (Frau Venus) como la soberana (Herrin) del nuevo despertar de la naturaleza. En el Jardín del Amor cortesano, donde los trovadores (Minnesänger) una vez salieron a celebrar la fiesta primaveral de Mayo (fröhliche Maifeste), Sandro instauró un antiguo ícono (Weihbild) del platónico, místico culto del alma (Seelenkult) (Warburg, 1932, vol I: 65).
\end{abstract}

Aunque no viene al propósito de nuestra interpretación, hay que señalar que la enorme mayoría de los estudiosos no comparten la identificación de Venus con Simonetta. De hecho, Warburg tenía pocos antecedentes que avalaran su interpretación en este punto pero, ciertamente fue acompañado en ella por Emil Jacobsen en un artículo publicado en el Preussische Jahrbücher durante el año 1898: "la joven sumida en sueños (in Träumen) es Smonetta, con los rasgos amados y sufrientes de sus últimos días" (Gombrich, 1985: 202).

Esta interpretación de Warburg sobre Botticelli que enlaza, a la vez, la tradición de la poesía del dolce stil nuovo con el neoplatonismo florentino encuentra una articulación textual preferencial en un texto que Warburg no podía ignorar. Nos referimos al comentario de Marsilio Ficino a la canción Donna me prega del filósofo Guido Calvacanti. En el texto ficiniano se produce la plena confluencia de la tradición poético-filosófica del dolce stil nuovo con el neoplatonismo florentino. Es necesario tener en cuenta que no llevaremos adelante una hermenéutica detallada de la filosofía del amor en Marsilio Ficino sino únicamente de aquellos puntos que son esenciales para la comprensión de la exégesis warburguiana de Botticelli. ${ }^{2}$

Las teorías del amor provenzal y la lírica toscana habían influido sobre Ficino según lo han demostrado los estudiosos (Kristeller, 1964: 287); sin embargo, su original hermenéutica del texto de Cavalcanti le permite al filósofo florentino condensar algunos puntos importantes de su metafísica del amor. De esta forma, la exégesis que llevaremos adelante no busca ser de ningún modo exhaustiva sino que pondremos de relieve únicamente aquellos puntos esenciales en Ficino para la comprensión de nuestra hipótesis sobre Warburg.

La tradición investigativa ha dedicado escasa atención a la exégesis ficiniana del texto de Cavalcanti y se ha limitado a señalar que la interpretación que propone Ficino del poema en clave de amor socrático masculino resulta una absoluta novedad en el Renacimiento (Nelson, 1958: 78-79). En efecto, Ficino inscribe su metafísica del amor produciendo una traslación de enorme importancia: mientras que en Cavalcanti el poema refleja la filosofía del amor heterosexual, para Ficino es posible reinterpretarlo como paradigma del amor platónico homoerótico aún si entendido en clave espiritual y cristiana. ${ }^{3}$ Precisamente, este gesto estará en la base de la polémica que desarrollarán Ficino y Pico della Mirandola (1463-1494) respecto de la naturaleza del amor (Aasdalen, 2011: 67-88).

Dado que de la interpretación de un poema se trata, conviene recordar que la distinción entre poesía y filosofía era altamente difusa en el Renacimiento italiano. De hecho, la Divina Comedia de Dante es la prueba de cómo poesía, filosofía y teología podían convivir como un mismo conjunto de lirismo y pensamiento. Ciertamente, en el caso de Ficino, la poesía resultaba tan esencial para él como la prosa a la hora de la interpretación filosófica. De este hecho testimonia la influencia de la lírica medieval
2. Para un estudio detallado de la exégesis ficiniana del Banquete de Platón y de la filosofía del amor en el neoplatonismo renacentista, cfr. Ciordia, 2004 y Ludueña Romandini, 2006.
3. Resulta de suma importancia la comparación del platonismo de Ficino con el de Poliziano, más aún teniendo en cuenta la relación de Ficino con la poesía. Sobre el particular, cfr. el excelente estudio de Storey, 2003: 602-619. 
y de los poetas provenzales sobre el propio Ficino y su filosofía. Del mismo modo, se pueden aproximar las reflexiones filosóficas de Ficino al Canzoniere de Petrarca pero también cabe mencionar la presencia de la poesía mística cristiana así como de los desarrollos de Buenaventura o Bernardo de Claraval.

Por estas razones, Pierre Laurens ha podido definir el propio estilo de Ficino como "una prosa lírica, quizá más propicia que el verso mismo para figurar las punzadas del alma amorosa" (Laurens en Ficino, 2002: LIV). No olvidemos tampoco que Ficino se presentaba a sí mismo como un adorador de la lira órfica y que, siguiendo la tradición neoplatónica de Proclo, estimaba que la prisca theologia había tenido su expresión primordial en la poesía y que la obra misma de Platón debía ser leída como una meditación en prosa de las formas poéticas primordiales de la filosofía. Nos hallamos, pues, frente a una auténtica theologica poetica donde la poesía es la ciencia suprema y el poeta como filósofo "expresa y a la vez oculta una sabiduría profunda tras las imagines con las que se expresa" (Granada, 2000: 75). De esta forma, tanto por su contexto cultural cercano como por su interpretación neoplatónica del corpus de los diálogos platónicos y por la influencia de la mística cristiana, la poesía se transforma, para Ficino, acaso en la forma suprema del ejercicio filosófico bajo el amparo del furor musaico.

Finalmente, resulta oportuno aclarar el sentido del tributo que decide rendir Ficino a la familia Cavalcanti por medio de su comentario de la canción Donna me prega. De hecho, a pesar de haber sido un averroísta, Ficino no duda en llamar "socrático" a Guido Cavalcanti pues su estrategia se inscribe en una reinterpretación platónica de la canción. Pero, al mismo tiempo, no puede soslayarse la presencia, en el círculo ficiniano, de Giovanni Cavalcanti (1448-1509), descendiente por vía indirecta del célebre Guido, el filósofo autor de Donna me prega. Giovanni Cavalcanti vivió por muchos años con Ficino en la villa de Careggi y fue quien lo instigó a la escritura del comentario al Banquete platónico. Por cierto, la admiración de Ficino por Guido Cavalcanti era inmensa dada su fama en el contexto cultural florentino hasta el punto que lo califica como "eminente servidor de su patria y superior a todos los de su siglo por la acuidad de su dialéctica" (Ficino, In convivium, VII, 1). Puede conjeturarse, entonces, que en el comentario de Ficino confluyen dos intenciones simultáneas: asentar su labor sobre la filosofía del amor en la tradición del gran Guido y, al mismo tiempo, homenajear a Giovanni Cavalcanti a quien Ficino llamaba su amico unico. Que ambas tareas podían ser convergentes puede apreciarse en el hecho de que Ficino le solicitó a Antonio Manetti que escribiese una biografía de Guido Cavalcanti para el uso de Giovanni Cavalcanti (Kristeller, 1937, vol. 2: 257). Por estas razones, no es imposible pensar que Ficino tuviese en mente un paralelismo poético-filosófico entre, por un lado Platón y Fedro (Allen, 1984) y, por otro, su amistad con Giovanni (Laurens en Ficino, 2002: LX). Esta hipótesis permitiría explicar así, de modo suplementario, la recuperación de la herencia platónica a través de un vínculo con el linaje Cavalcanti.

\section{La exégesis neoplatónica de Ficino acerca de la metafísica del Eros como resignificación de la tradición del dolce stil nuovo}

Aunque resulta manifiesto que Ficino utiliza para su propósito la totalidad del poema de Cavalcanti, se puede sostener que el centro de gravitación de la exégesis ficiniana del texto se encuentra en la segunda estrofa donde, haciendo referencia al amor, nos es dado leer:

In quella parte - dove sta memora

prende suo stato, - s'formato, - come

diaffan da lume, - d'una scuritate 


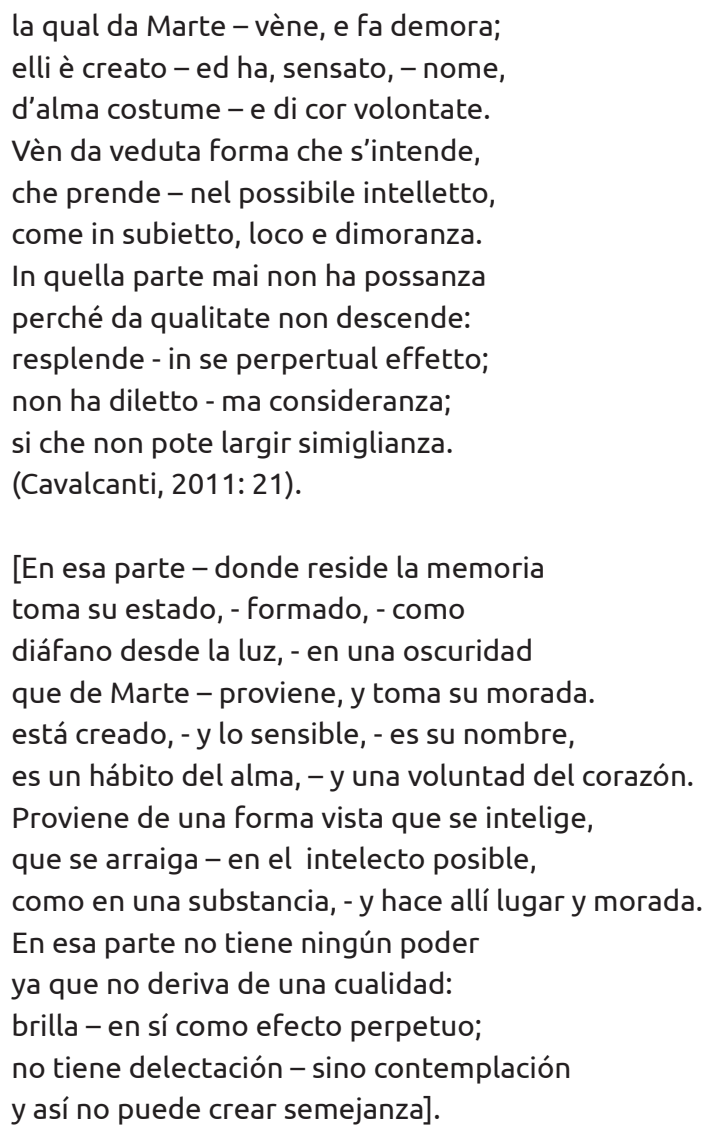

En cuanto al poema y sus numerosas alusiones escolásticas, ha podido atribuirse a Cavalcanti una filiación inequívocamente aristotélica y, más precisamente, averroísta (Nardi, 1954; Agamben, 2011) como lo demuestra la utilización de citas directas de textos de Averroes en versión latina o la distinción entre el intelecto posible y el intelecto agente. Aunque indudablemente Ficino debía estar en conocimiento de los elementos averroístas del poema de Cavalcanti, el filósofo florentino decide imprimir a los versos una reorganización neoplatónica y cristiana de la matriz averroísta. Es necesario excluir la posibilidad de una interpretación averroísta del poema de Cavalcanti por parte de Ficino dado que este último compuso una "confutatio Averrois" que se cuentan entre las más sólidas escritas durante el Renacimiento. En la concepción ficiniana, podemos encontrar una reorganización completa de la tradición aristotélico-averroísta:

El orden de la naturaleza exige además que haya un bien puro (bonum purum) y un bien intelectual (bonum intellectuale), un intelecto puro (intellectus purus) y un intelecto animal (intellectus animalis), un alma pura (anima pura) y un alma corporal (anima corporalis). El primero es Dios, el segundo el ángel, el tercero el alma racional y el cuarto es el alma irracional (Ficino, Theologia platonica, XV, 2).

En este sentido, para Ficino en su concepción neoplatónica y cristiana, Dios es el supremo Bien que debe colocarse por encima de cualquier intelecto y, por consiguiente, el intelecto puro e intelectual se corresponde con el ángel, eliminando así cualquier posibilidad de un intelecto agente que pueda subsistir separado de un orden natural que debe estar subordinado a hipóstasis precisas dentro de una jerarquía gobernada por Dios como soberano Bien. Esta reinterpretación por parte de Ficino fue también posible debido a la mediación, identificada por John Nelson, del comentario del Pseudo-Egidio a la canción de Cavalcanti que difumina su 
trasfondo averroísta para dar lugar a una lectura que hace del concepto aristotélico de lo "diáfano" el punto de articulación de una dialéctica entre la oscuridad y la luz (Nelson, 1958: 79).

Según la doctrina ficiniana que otorga el marco a la interpretación de la canción de Cavalcanti, la Belleza puede encontrarse en el cuerpo del amado, pero el verdadero amor se localiza en la renuncia a tocar el cuerpo que posee esta Belleza. El deseo de tocar y el deseo de amor comparten el mismo tipo de separación ontológica que existe entre la materia y lo inteligible hasta el punto en que uno implica la negación del otro. La sabiduría consiste entonces en saber distinguir y dominar estos dos tipos de deseo puesto que ambos se encuentran mezclados en la apariencia fenomenológica del mundo. La belleza corporal tiene el poder de despertar el deseo de tocar en el sabio, pero la prueba de sabiduría consiste no solamente en resistir a la tentación sino, sobretodo, en reconocer el carácter idolátrico de la belleza hacia la cual el sabio se siente atraído. Sabio será entonces aquel que llegue a darse cuenta de que lo que ama no es la belleza del cuerpo del amado, sino la fuerza divina que lo modela y que actúa en su interior.

Contrariamente a lo que podríamos creer, la rehabilitación llevada adelante por Ficino de la teoría platónica y plotiniana de la doble Venus, celeste y pandémios, que sirve para distinguir el amor sagrado del amor profano, no introduce ningún cambio en el sistema expuesto hasta aquí. En primer lugar, debido a que la Venus vulgar no supone la reivindicación de la materia, sino más bien el reconocimiento de la presencia de lo divino en lo material, lo que es completamente distinto. De hecho, la Venus vulgar recibe las chispas de la Belleza divina a través de la Venus Celeste y las transmite luego a la materia sobre la que influye. En segundo lugar, cuando Ficino sostiene que la generación es la expresión del amor pandémios, no quiere decir con esto que la belleza está constituida por el cuerpo engendrado sino que afirma que la Belleza se extiende hacia los cuerpos humanos a través de la generación, y esta Belleza no se confunde jamás con el cuerpo que ella modela.

Esta dinámica es posible gracias al hecho de que el objeto de amor es la belleza "incorporal" del amante. Ficino hace explícito el núcleo fundamental de su metafísica del amor cuando habla de la "óptica" del fenómeno amoroso. De hecho, Ficino establece que el amante no ama la belleza corporal de su amado sino más bien el fantasma de esta belleza que se encuentra en el espíritu del amante. Ficino sugiere así que la esencia de la belleza es guardada, bajo la forma de un fantasma, en el espíritu de quien la percibe. No podemos percibir la inmensidad del cielo con nuestra pequeña pupila, sin embargo, tenemos en nuestro espíritu una imagen muy clara de la belleza del cielo y esta imagen deviene en el objeto de nuestro amor.

Para que la dinámica de esta teoría del amor basada en los simulacros y las imágenes pueda tener lugar, Ficino se apoya por completo en la teoría del spiritus y es imposible comprender la erótica de los muchachos que propone el florentino sin tener en cuenta este concepto fisiológico y cosmológico fundamental. ${ }^{4}$ En una de sus más

notables definiciones del concepto, Ficino establece que el spiritus es

Un cuerpo muy sutil, casi un no-cuerpo y casi un alma; o casi una no-alma y casi un cuerpo. En su composición hay un mínimo de terrestre, algo más de acuático y mucho más de una naturaleza aérea. Pero en su mayor medida participa de la naturaleza del fuego estelar [...] Es al mismo tiempo brillante, caliente, húmedo y revigorizante (Ficino, 1576: 535).

Para Ficino, el spiritus resulta una especie de corpúsculo luminoso generado por el calor de la sangre y que penetra todo el cuerpo interactuando con el alma para 
posibilitar el fenómeno mismo de la vida. Por consiguiente, al tratarse de un vapor sanguíneo es el espejo donde las influencias astrales actúan sobre el cuerpo humano. Al mismo tiempo, la noción de spiritus presupone una teoría de la óptica y produce una teoría de la magia que, como en el caso de Ficino, ha tenido una enorme difusión durante el Renacimiento y sobre la cual queda aún mucho trabajo por realizar. Sin embargo, querríamos señalar aquí la relevancia de esta noción en la teoría del amor de Ficino. En efecto, podemos apreciar ahora la importancia del spiritus en la fisiología y la metafísica ficinianas del amor puesto que es en el spiritus del amante donde la imagen del amado se refleja como en un espejo.

Este espejo de imágenes sensoriales permite al alma realizar la comparación entre la imagen recibida desde el mundo exterior y aquella que esta posee de manera innata y que refleja la idea pura de la Belleza. Pero, justamente, como el spiritus no es sino un espejo donde se reflejan las imágenes, la ausencia del amado hace que su imagen se desvanezca, a pesar de la existencia de la memoria del alma. La presencia del amado es entonces necesaria para que su imagen reflejada en el espejo del spiritus pueda ser "iluminada" y "encendida". Sin embargo, la necesidad de la presencia del amado frente al amante deja entrever un papel aún más importante para el spiritus en esta onto-fisiología del amor. En efecto, Ficino llega a describir la esencia del amor como un intercambio de espíritus.

Como corolario, la función del spiritus no consiste solamente en ser un espejo para el alma donde se reflejan las imágenes sensibles sino que constituye la sustancia misma que se intercambia entre los amantes en el fenómeno del amor. A través del spiritus, es la sangre misma que se transmite del amante al amado estableciendo una circulación fisiológica de los vapores sanguíneos por medio de la vista. Esta circulación explica la prosecución del amado por parte del amante dado que este debe recobrar la homeostasis de su sistema sanguíneo y de su spiritus. Sobre esta tela de fondo doctrinal, es posible ahora comprender la exégesis ficiniana de la canción de Cavalcanti que Ficino expresa del siguiente modo:

Todo esto, me parece, lo ha plasmado el filósofo Guido Cavalcanti en sus versos con un arte consumado. De igual modo que un espejo, alcanzado desde un cierto ángulo por el rayo del sol, se ilumina oportunamente y, por el reflejo de este esplendor, inflama la lana que se encuentra próxima, así, piensa él [Cavalcanti], esta parte del alma que se llama imaginación y memoria obscura (obscuram phantasiam uocat atque memoriam), como si fuera un espejo, es alcanzada por la imagen de la belleza, la cual toma el lugar del Sol si bien esta modela a partir de ella una segunda imagen, que es como el reflejo brillante de la primera, y por medio de la cual, siguiendo el ejemplo de la lana, se inflama de amor. Añade que este primer amor es encendido por el apetito de los sentidos y engendrado por la belleza del cuerpo percibido por los ojos; pero que esta forma ya no está grabada en la imaginación del mismo modo que en la materia del cuerpo, sino al contrario sin materia, y de tal manera que es la imagen de un hombre determinado en un lugar y un momento bien precisos. Esta imagen, a su vez, enciende un reflejo que ya no es semejante a un cuerpo humano particular sino que es la razón universal (ratio communis) y la definición del género humano en su totalidad [...] De este reflejo y razón universal de la inteligencia (mens) nace de la voluntad otro amor que no tiene nada que ver con el comercio del cuerpo (commertio corporis). Coloca al primero en el placer (uoluptate) y al segundo en la contemplación (contemplatione) [...] Piensa que en el hombre estos dos amores combaten entre sí, uno conduciendo a la vida voluptuosa y bestial y el otro produciendo una exaltación hacia la vida contemplativa y angélica [...] ¿Quién no ve, entonces, en estas palabras a los dos amores, el celeste y el vulgar? (Ficino, In convivium, VII, 1). 
5. Ficino retoma la diferenciación entre las dos Venus de Platón (Banquete, 180d-182b).
Como puede apreciarse, la exégesis ficiniana de la canción de Cavalcanti se apoya sobre la posibilidad de concebir al objeto amado como fantasma. En este sentido, Ficino recobra la tradición de interpretación del fenómeno amoroso por medio de la noción de spiritus que ya se encontraba presente en el dolce stil nuovo. Para Cavalcanti, la dinámica del amor es fundamentalmente pneumatológica pues no es en otro lugar que en el propio spiritus donde el amante recibe la imagen de la dama amada y, gracias a él, nace la posibilidad misma del amor (spirito d'amare). Apoyándose en Alejandro de Afrodisia y en la tradición averroísta, para Cavalcanti "la experiencia del círculo pneumático va de los ojos a la fantasía, de la fantasía a la memoria y de la memoria a todo el cuerpo [...] en perfecta simetría espíritu-fantasma" (Agamben, 2011: 183). Dentro de esta perspectiva, Ficino puede sostener que el spiritus con su presencia material pero sutil, produce una mixis de vapores sanguíneos que hacen que los amantes permuten su lugar subjetivo en la indistinción sensible de los cuerpos. Por otro lado, como el contacto sexual debe ser cuidadosamente evitado, el amante debe utilizar la flama sensible de su alma para activar un reflejo de la imagen del amado quien queda, por así decirlo, desprovisto de todas sus cualidades particulares para elevarse al estatuto más general posible.

En otros términos, lo que comienza como la atracción por un cuerpo sensible, gracias a la mediación del spiritus, concluye en un proceso de ascenso inteligible que lleva a la adoración del Homo como definición del género humano en cuanto tal. La potencia amorosa permite, según una rigurosa lógica de los afectos, pasar del cuerpo individuado a la pasión por el Universal. El verdadero amor, según Ficino, es aquel en el que los sujetos de la atracción sensible pierden todos sus atributos individualizantes para dirigirse a una des-individualización completa que permite amar no ya a un sujeto concreto sino a la razón universal y, por tanto, posibilita el ascenso hacia Dios como punto de fuga en el que debe converger todo el amor humano. De esta forma, Ficino altera profundamente la intención averroísta de la canción de Cavalcanti pero, aún bajo los auspicios de una teología platónica cristiana, conserva los rasgos de una concepción del amor en todo equivalente a la desubjetivación de los amantes que, buscando amarse entre sí en lo inaprehensible de los cuerpos, encuentran el equivalente universal del amor en la cifra oculta de la divinidad.

Por cierto, el camino no está exento de tensiones y las pasiones del cuerpo dificultan el ascenso metafísico recordando que, en la mayor parte de los casos, habrá que lidiar con una polaridad o tensión entre los apetitos y la vía contemplativa. De allí que Ficino haga resurgir la oposición entre las dos Venus. En el contexto del Renacimiento italiano, la problemática de las dos Venus, la Profana y la Celeste, ${ }^{5}$ encuentra sus raíces ya en el De voluptate de Lorenzo Valla (1431) y alcanza un punto culminante en la obra ficiniana donde el placer los cuerpos es desplazado a favor de un horizonte celestial y, por tanto, la verdadera felicidad no es sino una suerte de paradójica voluptuosidad contemplativa. La temática, por cierto, tendrá una enorme irradiación sobre las artes que puede observarse en los motivos venusinos de las obras de Botticelli, Mantegna y Ticiano (Wind, 1958: 141-151).

\section{Conclusiones: Aby Warburg, el Eros y la locura}

Es posible establecer que, más allá de las discrepancias propias de las tradiciones filosóficas y ciertas diferencias de detalle, existe una convergencia interpretativa de la fantasmática del amor en Cavalcanti y Ficino (Couliano, 1987). Ahora bien, de la exégesis que Ficino realiza de la canción de Cavalcanti podemos extraer la siguiente formulación que adquiere un valor epocal. Lo denominaremos, por mor de claridad, el teorema ficiniano del amor: donde hay amor es porque se ama el fantasma. Su corolario se enuncia: el anudamiento sexual de los cuerpos es un imposible ontológico 
que el fantasma, al mismo tiempo, impele y prohíbe. Con todo, la imposible relación sexual tiene como culminación la fusión universal de los cuerpos no sexuados en la mixis de la simpatía cósmica universal. El Uno indiferenciado de los cuerpos garantiza su imposible discriminación sexual. El fantasma transforma los impulsos del deseo sexual en juegos ornamentales de la armonía retórica de la palabra que no es sino el reflejo en el discurso de la metafísica de un cosmos unificado por el principio de la armonía suprema según el cual existe una correspondencia sin resto entre macrocosmos y microcosmos y, por tanto, todo se encuentra en todo.

En 1924 Aby Warburg compra parte de la biblioteca de Franz Boll luego de la repentina muerte de este último y le encarga a Rudolf Larisch, uno de los más grandes tipógrafos y diseñadores gráficos austríacos del siglo XIX y principios del siglo XX, la creación del exlibris. Como figura, utilizó a un astrónomo en meditación correspondiente a la edición veneciana de 1494 del Astrolabium planum de Angelus, y en los contornos mandó a inscribir el lema Per monstra ad Sphaeram para evocar la lucha del héroe contra el monstruo. Sin duda la mención de la Sphaera se debe a la obra maestra homónima de Franz Boll (publicada en Leipzig en 1903) que Warburg utilizó de manera decisiva para su desciframiento de los frescos astrológicos del Palazzo Schiffanoia de Ferrara. Como lo ha demostrado Davide Stimilli, el motivo tiene inspiración en el lema de Kepler "per aspera ad astra" ("por el sendero áspero, hacia las estrellas"). Cabe señalar que el lema tiene raíces clásicas en Cicerón, Séneca y Virgilio pero Warburg podría haberla tomado asimismo del Conde August von der Lippe (Stimilli, 2013: 5).

Justamente, Boll había mostrado en su obra que los astrólogos, en su necesidad de aumentar el número de los signos celestes para la lectura del futuro, empezaron a subdividir las constelaciones. Se propagó de este modo una ciencia ficticia en la que había una imagen diferente para cada astro que presidía cada día, esto es, los denominados paranatellonta. Los catálogos tardo-antiguos que daban cuenta de estas innúmeras constelaciones ficticias representadas con monstruos de toda especie provenientes de la mitología clásica, es lo que Boll llamó la Sphaera Barbarica. Esta profusión de imágenes no sólo fue una fuente histórica de inspiración para Warburg sino también un caudal de pánico ante la proliferación de la agencia demónica de las imágenes de los antiguos.

Como sabemos, estas constelaciones ficticias, se pensaba, estaban dotadas de eficacia mágica. Y Ficino, precisamente, había estudiado la magia de los talismanes, es decir, la inscripción de estas imágenes en piedras determinadas con la intención de lograr la atracción mágica de las potencias cosmológicas y demónicas según las rigurosas leyes de la signatura universal entre el macro y el microcosmos. Esas potencias demónicas eran los primeros monstruos que Warburg quería conjurar.

De modo general, podemos afirmar que una suerte de triplicidad se constituye entre los cuerpos, el fantasma y la sexualidad que marca, en sus distintos regímenes históricos, las configuraciones civilizacionales del deseo. ${ }^{6}$ El Renacimiento constituyó un punto de ruptura del que Ficino es una cifra prístina, quizá propia de las Letras Humanísticas, pero no por ello menos reveladora de una mutación antropológica que estaba acaeciendo. Hoy en día, en cambio, estamos en posición de considerar el legado del colapso de Warburg en la locura, vale decir, la caída del sostén fantasmático y el ascenso de los demonios corporales, de la sexualidad desvelada, rasgada, como un nuevo hito civilizacional: la era tecnológica de cuya irrupción Warburg estaba tan fascinado como aterrorizado se muestra capaz de operar un nuevo reordenamiento de la serie triple de los cuerpos, el fantasma y la sexualidad.

La escisión neoplatónica entre la Venus Profana y Celeste que determina la interpretación ficiniana del poema de Cavalcanti sugiere algunas correspondencias. Así los
6. Aunque aquí nos ocupamos primordialmente del deseo sexual, resulta de enorme provecho aproximar las investigaciones warburguianas a las corrientes del "giro afectivo". Sobre esta última tendencia filosófica, cfr. Macón, 2013: 1-32. 
7. La temática es aproximable, justamente, al antagonismo entre Eros y Narciso pues este último se defiende del primero temiendo "la locura, la amenaza de caos y la esterilidad" (Abadi, 2018: 63).
8. Para un análisis detallado de este concepto central de Warburg y de la bibliografía especializada, cfr. Didi-Huberman, 2002: 191-202. monstra y la sphaera del lema de Warburg se alinean con la escisión que la historia de la metafísica establece sobre las pasiones del cuerpo que no puede domeñar. ${ }^{7}$ Un sistema de equivalencias alternas se establece: los monstra ocupan el lugar de los démones y el cuerpo sexuado. Y luego, la sphaera (astra) halla su lugar mas propio en la contemplación del universo matematizado y, por tanto, distanciado. Esta serie de alternancias establece, por así decirlo, la Spaltung de la historia de la metafísica.

La esquizofrenia de la historia de la metafísica es el locus donde se sitúa, precisamente, el colapso y la "división" psíquica de Warburg (siguiendo así toda la tradición metafísica platónico-aristotélica que privilegia la contemplación). El fantasma en el espejo cósmico revela la imago solar (divina). Sólo el sujeto, en su furor, cree ser la imagen de las potencias cósmicas. Pero si rasga el velo de ese fantasma descubrirá que es un reflejo imaginal aprés coup, el efecto de sutura de un vacío constitutivo. La agencia metafísica de la imagen toca así a su fin, lo cual no quiere decir que no haya agencia sino que hoy es necesario pensar una agencia imaginal post-metafísica como lo demuestran fundamentales tendencias en curso (Fleisner, 2017: 289-311).

El final de la metafísica es el final de la idea de fantasma como agencia. En todo caso, hay un vacío de la imagen-fantasma. La filosofía por venir debe ocuparse, ciertamente, del "patetismo" de la imagen (el Pathosformel warburguiano) pero para superar el plano de su figurabilidad, podría resultar provechoso reflexionar sobre la presencia y el aparecer en función del vacío como imposible de la imagen y, a la vez, condición de posibilidad de su manifestación. Este camino había sido entrevisto, curiosamente, por los iconoclastas quienes no tenían tanto animadversión hacia la imagen cuanto al vacío de figurabilidad que ella recubre con su velo. Este presentimiento no podía sino despertar la furia de los iconoclastas (es decir, su temor ante las imágenes-fantasma). No es aventurado pensar que Warburg, por ser un heredero de la metafísica además de un historiador y un antropólogo de la imagen, es muy posible que haya captado ese vacío en el momento de su colapso.

Así las cosas, resulta esencial en Warburg y su concepto central de Pathosformel ${ }^{8}$ no tanto la repetición de la imagen o del gesto ni el "entre" de las imágenes colocadas en el Atlas, sino la certeza de que el Pathos es un polo en tensión con la Forma o, dicho de otro modo, que el Pathos es causante de la Spaltung de la Forma. La potencia del fantasma es el hechizo que encubre su vacío, el cual busca colmarse mediante la transmigración histórica del Pathos en distintas fórmulas. Este es el sentido profundo del Nachleben: el Pathos transmigrante no puede velar la afigurabilidad que habita toda forma-imagen. En otras palabras, Warburg había advertido en Botticelli un dualismo entre la implicación personal (pathos) y la distancia (fórmula) que él denominaba Denkraum (espacio del pensamiento). Dicho espacio era la herramienta que actuaba como salvaguarda de lo que Warburg estimaba como la locura que las potencias fantasmáticas de las imágenes podían producir en una humanidad no consciente su eficacia.

Si seguimos el diagnóstico warburguiano prolongando su estela y las potencias que habitan la imagen conducen al vacío, la filosofía futura deberá confrontarse con algunos interrogantes fundamentales: ¿qué queda de la potencia de las imágenesfantasma una vez que su arché ha sido puesta al desnudo? ¿Cuál es la metamorfosis contemporánea, en las sociedades hipertecnológicas, de los démones que tanto atemorizaban a Warburg?

Cuando Ficino comenta a Cavalcanti, la elevación de la imagen al rango del objeto causa del amor implica la forclusión del cuerpo y la aceptación del axioma según el cual la relación sexual es un imposible metafísico antes que moral. La imagen es la sutura metafísica de la ausencia postulada del cuerpo. Pero se descifra, en la teoría 
de Ficino, una consecuencia de amplio alcance: el cuerpo no existe, sólo hay imagen agente del cuerpo. No deseamos el cuerpo del otro sino su imagen agente en nosotros (en nuestro spiritus). El nihilismo cosmológico contemporáneo afecta el teorema de Ficino. Este es el punto donde nos encontramos hoy, herederos como somos, no tanto de Warburg como del colapso de Warburg.

La imagen parece haber multiplicado sus capacidades de agencia en una escala sin precedentes. Sin embargo, el teorema de Ficino no puede ya sustentar la presencia del fantasma y darle gravedad. El retorno de lo demónico y de la Venus pandémios ha rasgado los cuerpos contemporáneos que no se encuentran ni siquiera en un instante fantasmático. Esto quiere decir que el fantasma ya no tiene el poder de velar el vacío que habita en los cuerpos. En cierta forma, el legado del colapso de Warburg ha dejado en evidencia el teorema del placer contemporáneo: el Uno se ha desmultiplicado en cuerpos rasgados haciendo de la sexualidad un imposible pues el fantasma ya no puede disfrazar la desagregación de los cuerpos. La caída del fantasma es, asimismo, el quiebre del Occidente de los saberes renacentistas y el fin de la era del Humanismo. Sostenida en una sinergia de los fantasmas, la Modernidad avanzó hasta su ocaso contemporáneo: una nueva etapa civilizacional se diseña y cabe preguntarse si podrá dar nacimiento a una nueva fantasmática o se agotará en las materialidades exangües y difusas o, dicho de otro modo, en la materia objetivada por el valor-dinero, último resabio del intercambio universal en el mercado global de los cuerpos.

El malestar contemporáneo de la cultura no es sino una crisis de la capacidad de los fantasmas para custodiar el plus-de-cuerpo que todo cuerpo necesita para sostenerse. Agotando su recorrido histórico, la emigración de los fantasmas se presenta como la epopeya de una manía de la que Warburg ha sido un testigo privilegiado tanto en su lectura de los textos e imágenes renacentistas como en su tormento psíquico. Tal vez no sería una mala apuesta el intentar habitarla. 


\section{Dibliografía}

" Aasdalen, U. (2011). The First Pico-Ficino controversy. En Clucas, S., Forshaw, P., Rees V., (Eds.). Laus Platonici Philosophi. Marsilio Ficino and his influence. Leiden: Brill, 67-88.

》Abadi, F. (2018). El sacrificio de Narciso. Buenos Aires: hecho atómico ediciones.

»Agamben, G. (2011). Stanze. La parola e il fantasma nella cultura occidentale. Torino: Einaudi.

" Allen, M. (1984). The Platonism of Marsilio Ficino : A Study of His Phaedrus Commentary, Its Sources and Genesis. Berkeley: University of California Press.

» Cavalcanti, G. (2011). Rime. Edición de R. Rea \& G. Inglese. Torino: Einaudi.

»Ciordia, M. (2004). Amar en el Renacimiento. Un estudio sobre Ficino y Abravanel. Buenos Aires: Miño y Dávila Editores.

»Couliano, I. P. (1987). Eros and Magic in the Renaissance. Londres: The University of Chicago Press.

"Didi-Huberman, G. (2002). L'image survivante. Histoire de l'art et temps de fantômes selon Aby Warburg. Paris: Éditions de Minuit.

» Ficino, M. (1576). Opera Omnia. Basileae: ex officina Henricpetrina.

"Ficino, M. (1964-1970). Theologia Platonica de immortalitate animorum / Théologie platonicienne de l'immortalité des âmes. (Edición y traducción de R. Marcel). Paris: Les Belles Lettres.

"Ficino, M. (2002). Commentarium in Convivium Platonis, De Amore / Commentaire sur Le Banquet de Platon, De l'amour. (Edición y traducción francesa de Pierre Laurens). Paris: Les Belles Lettres.

» Fleisner, P. (2017). La joya del chiquero. Apuntes sobre los animales y las mujeres desde una estética posthumana. En Cragnolini, M. B., (Ed.). "Quién" o "qué". Los tránsitos del pensar actual hacia la comunidad de los vivientes (pp. 289-311). Adrogué: La cebra..

"Gombrich, E. (1985). On the Renaissance. Volume 2: Symbolic Images. Londres: Phaidon Press.

"Granada, M. A. (2000). El Umbral de la Modernidad. Barcelona: Herder.

» Klein, R. (1965). Spirito peregrino. Revue des études italiennes, XI, 197-236.

" Kristeller, P. O. (1964). The Philosophy of Marsilio Ficino. Gloucester (Massachusetts): Peter Smith.

» Kristeller, P. O. (1937). Supplementum Ficinianum. 2 volúmenes. Firenze: Leo. S. Olschki.

»Ludueña Romandini, F. (2006). Homo oeconomicus. Marsilio Ficino, la teología y los misterios paganos. Buenos Aires: Miño y Dávila Editores.

» Ludueña Romandini, F. (2017). La ascensión de Atlas. Glosas sobre Aby Warburg. Buenos Aires: Miño y Dávila Editores.

" Macón, C. (2013). Sentimus ergo sumus: el surgimiento del "giro afectivo" y su impacto sobre la filosofía política. Revista Latinoamericana de Filosofía Política, 
Vol. II, $n^{\circ} 6,1-32$.

»Nardi, B. (1954). Noterella polemica sull' averroismo di Guido Cavalcanti. Roma: Editrice Universale di Roma.

"Nelson, J. (1958). Renaissance Theory of Love: The Context of Giordano Bruno's Eroici Furori. Nueva York: Columbia University Press.

»Platón (1998). Symposium. (Edición y traducción de C. J. Rowe). Warminster: Aris \& Philips.

» Stimilli, D. (2013). Aby Warburg's Impresa. Images Re-vues. Histoire, anthropologie et théorie de l'art. Hors-série 4. Survivance de d'Aby Warburg, 1-26.

» Storey, C. (2003). The Philosopher, the Poet, and the Fragment: Ficino, Poliziano, and Le stanze per la giostra. Modern Language Review, 98 (3), 602-619.

»Verbeke, G. (1945). L'évolution de la doctrine du Pneuma du stoïcisme à saint Augustin. Etude philosophique. Paris: Desclée de Brouwer.

»Warburg, A. (1932). Gesammelte Schriften. (Edición de Gertrud Bing). 2 volúmenes. Leipzig: Teubner.

"Wind, E. (1968). Pagan Mysteries in the Renaissance. An exploration of philosophical and mystical sources of iconography in Renaissance art. Nueva York: W.W. Norton \& Company. 
